\title{
Dificuldades de Emancipação. Observações sobre a Teoria do "Teatro do Oprimido"*
}

\author{
Olivier Neveux \\ Universidade Lyon 2, França \\ oneveux@gmail.com \\ Tradução: Viviane Juguero \\ vivianejuguero@yahoo.com.br
}

\section{Resumo}

Escrever sobre o "Teatro do Oprimido"(TO) pressupõe delimitar previamente o que será discutido. Trata-se de um método teatral praticado vigorosamente em todo o mundo, o qual segue orientações antagônicas justificadas por meio de diversos enfoques de seu criador, o diretor brasileiro Augusto Boal (1931-2009). O presente trabalho pretende contribuir com as discussões que o geraram, ou seja, com a densa e complexa base teórica que fundamenta e retifica o TO de acordo com a história e com as práticas. O objetivo é estudar, de alguma maneira, a política de uma teoria- entre as mais importantes - do "teatro político"** em relação aos seus questionamentos originais, às modificações no decorrer da história, aos acontecimentos e ao tempo de desenvolvimento, da forma como acontecem, particularmente na França. A qualificação do TO se preocupará, consequentemente, somente com aquilo que se pratica a partir de inquietações sustentadas por uma perspectiva emancipatória e não com as numerosas formas normativas que alegam, contudo, preocupações de diminuir todos os conflitos sociais ou de reconciliar os oprimidos com a ordem que os oprime ${ }^{\star \star \star}$.

\section{Palavras-chave}

Teatro do oprimido. Teatro político. Emancipação
Writing on the «Theater of the Oppressed» (TO) presupposes delimiting previously what will be discussed. It is a theatrical method practiced vigorously throughout the world, which follows antagonistic orientations justified by several approaches of its creator, the Brazilian director Augusto Boal (1931-2009). The present work intends to contribute with the discussions that have generated it, that is, with the dense and complex theoretical base that bases and rectifies the TO according to its history and practices. The aim is to study, in some way, the politics of a theory - among the most important ones - of the «political theater» in relation to its original questions, its changes in history, the events and the time of development, the way they happen, particularly in France. The qualification of the TO will therefore only concern itself with what is practiced on the basis of anxieties sustained by an emancipatory perspective and not with the numerous normative forms which, however, allege concerns of diminishing all social conflicts or reconciling the oppressed with the order that oppresses them. Mots clés

Theater of opressed. Political theater. Emancipation.

\footnotetext{
* Publicado originalmente em NEVEUX, Olivier. Difficultés de l'émancipation. Remarques sur la théorie du “Théâtre de l'opprimé". Tumultes. n ${ }^{\circ} 42$, p. 191-207, 2014. DOI 10.3917/tumu.042.0191

** Isso implica abandonar o aspecto terapêutico da técnica chamada "O arco-íris do desejo", desenvolvida por Boal na obra intitulada: O Arco-Íris do desejo. Do teatro experimental à terapia, traduzida do português (Brasil) por J. Boal. Paris, Editora La Découverte, 2002.

${ }^{* * *}$ Assim, em uma obra recente: "Desde o teatro do povo, teatro do trabalhador, no qual se viu a política entrar em cena, seguido do teatro do oprimido de Augusto Boal, nos anos 1970, foram esboçados os contornos disso que faz o teatro empresarial de hoje em dia". L. Lesavre, Scènes de management. Le théâtre au service de l'entreprise, Grenoble, Presses Universitaires de Grenoble ("Management et innovation), 2013, p. 14 e também pp. 57-58)
} 


\section{sangue dos outros}

Um relato tem valorfundador. No final dos anos 1960, o Teatro de Arena de São Paulo, no qual Augusto Boal écoordenador, atravessa, em uma vila do Nordeste, o caminho de um agricultor, Virgílio, por ocasião da turnê de um de seus espetáculos militantes, uma peça que encerra com uma viva exortação: "Derramemos nosso sangue pela liberdade! Derramemos nosso sangue por nossa terra! Derramemos nosso sangue, vamos derramá-lo!".Convite levado ao pé da letra por um camponês que os convida a se unirem, junto com suas armas, a uma ação, naquele dia, contra um latifundiário. A trupe declina: suas armas são adereços cênicos. Virgílio insiste: eles terão as armas,que os atores venham. O Teatro de Arena, envergonhado, resignado, temde reconhecer que não sabe manejá-las. Assim, constata Virgílio, "[...] compreendo bem a sinceridade estética de vocês: o sangue que vocês pensam em derramar é o nosso e, sobretudo, não é o de vocês." A cena é edificante e embasa o contexto que justifica, segundo Boal, a criação do TO: opor-se a uma arte com um discurso irresponsável, pronta a derramar "o sangue dos outros" com a mais perfeita das boas consciências, sendo visionária e prescritiva.

Foi assim que Boal cria progressivamente e empiricamente, em vista das diferentes conjunturas e situações que atravessa (o Brasil dos anos 1960, a ditadura e o exílio, a Europa, etc.), um "método teatral": o TO (que compreende diversas formas: Teatro invisível, Teatro-fórum, Teatro-jornal, Teatro-mito, Teatro-imagem, Teatro-folhetim, etc.). Essa criação está, portanto, relacionada com a dimensão polêmica que

1 Boal, L'Arc en ciel du désir. Du théâtre expérimental à la thérapie, op. cit., p. 8. O relato desse encontro inicia a obra. a gerou e com os fatos históricos e políticos que a justificaram. Ela se constitui, com efeito, em um período repleto de afrontamentos políticos e sociais, como uma proposta teatral conflitante, em meio à constelação, heterogênea, do "teatro vermelho": "O teatro político era assim. Ele te mostrava o caminho. [...] O teatro político de antes era unívoco, oferecia as boas respostas ${ }^{3}$. Essa invenção deduz ou traduz as questões estéticas, as questões da "poética", da "função social e histórica" que estavam vinculadas ao teatro. Mas essa dinâmica ajustada à conjuntura das situações de sua análise, expõe o paradoxo de suas características dominantes, desdobrando-se em uma outra argumentação. É possível, com efeito, denotar uma tensão presente ao longo de toda a sua história, ou melhor, uma oscilação entre duas lógicas não dialetizadas: esquematicamente, uma seria "teleológica", a outra "histórica". Boal se embasa na história do teatro - não sem introduzir alguns mitos ("Em sua origem, o teatro era canto ditirâmbico: o povo livre cantando ao ar livre. O carnaval. A festa" 4 ): desenvolve os movimentos com base em considerações antropológicas, reflexões históricas e a partir de uma análise de classe. Essa leitura resulta, in fine, na construção do TO, na conclusão de uma trajetória perfeita, como uma encarnação redentora ou como uma resolução das contradições que caracterizavam as intervenções do

2 Sobre esse tipo de teatro no Brasil, ver J. Boal, in C. Biet, O. Neveux (sob a direção de), Une histoire du spectacle militant. Théâtre et cinéma (1966-1981), Vic la Gardiole, L'Entretemps, 2007, pp. 216-227 e, na França, O. Neveux, Théâtres en lutte. Le théâtre militant en France de 1960 à nos jours, Paris, La Découverte, 2007.

3 . Boal, Jeux pour acteurs et non-acteurs. Pratiques du Théâtre de l'opprimé (1978), traduzido do português (Brasil) por R. Mellac nas edições anteriores e por V. Rigot-Müller na obra presente, Paris, Editions La Découverte, 200439.

4 A. Boal, Théâtre de l'opprimé, traduzido do espanhol por D. Lémann, Paris, Librairie François Maspero, 1977, p. 11. 
teatro precedente e, muito particularmente, do teatro político. O TO seria a concretização, o ápice do teatro, produtodo triunfo da astúcia da razão política sobre as desmedidas e impasses precedentes. Entretanto, essa conclusão coincide, simultaneamente, tanto em outras declarações quanto no mesmo texto, com a historicização de sua invenção ("Em uma sociedade que tenha realizado sua revolução, eu penso, curiosamente, que deveria retornar ao teatro aristotélico"5) e de seus recursos ("É um teatro que tem seu lugar dentro de um certo processo, e que pode intervir em certos momentos mas não em outros"6).

Esta dualidade (forma advinda do teatro dos oprimidos/relação contraditória com a conjuntura) não é articulada jamais. Ela se remete ao cerne próprio da crítica que Boal tece sobre Brecht e o "teatro épico". Sua contestação se organiza a partir de um ponto de vista sistematicamente político, mas em tensão, como se elas fosse autônomas, com a crítica de sua obsolescência histórica - "Eu não sei se as técnicas do teatro do oprimido seriam possíveis no tempo de Brecht, pois Brecht precisava lutar contra uma fórmula estável de teatro existente na Alemanha"7 - e sua obsolescência "dramática”. É esse último ponto, contudo, o que se revela mais determinante. A proposição teórica se nutre, com efeito, como o teatro épico, de uma contestação do aristotelismo e de seu

\section{Idem, p. 192.}

6 A. Boal, Le "Théâtre de l'opprimé". (Entrevista com Augusto Boal, Emile Copfermann, Patrick Sempéray e Pierre Razdac)", Critique communiste, №28, 1979, p. 30.

7 Idem, p. 22. Ver também A. Boal, "Aux limites du théâtre d'intervention : le "Théâtre de l'opprimé" en France, in J. Ebstein et $\mathrm{P}$. Ivernel (organizados e apresentados por), Le théâtre d'intervention depuis 1968. Tome II, Lausanne (Suisse), L'Age d'Homme, 1983, p. 161. "sistema trágico-coercitivo"8 mas pretende "ultrapassar" Brecht - em seu projeto de uma "dramaturgia não-aristotélica", sendo apenas um primeiro passo, parcial e limitado, em relação à "conquista dos meios de produção teatral"10 pelos próprios oprimidos:

\begin{abstract}
A poética de Brecht é aquela das vanguardas esclarecidas: mostra-se um mundo transformável e a transformação começa no próprio teatro. O espectador não delega poder para que alguém pense em seu lugar, mesmo que continue a delegar para que alguém atue no seu lugar. A experiência é reveladora no nível da consciência mas não globalmente no nível da ação. A ação dramática elucida a ação real. O espetáculo prepara à ação ${ }^{11}$.
\end{abstract}

Brecht ocupa, portanto, de qualquer maneira, um lugar terminal na genealogia da usurpação da expressão dos oprimidos pela dominação. A esse respeito, quaisquer que sejam os avanços evidenciados em seu teatro "marxista" - e Boal salienta a importância dessa contribuição -, ele continua subordinado à lógica da "desapropriação" que se organiza seguindo as modalidades mais ou menos francas e radicais do teatro ocidental. Em um texto de 1981, Boal escreveu: "Brecht disse que o teatro devia servir à revolução! Ele não está a serviço: ele é parte integrante da revolução, é a preparação da revolução, é seu estudo, sua análise, o ensaio geral da revolu-

\section{Idem, pp. 79-122.}

9 Ver B. Brecht, "La dramaturgie non aristotélicienne (19321951), in B. Brecht, Ecrits sur le théâtre, edição realizada sob a direção de J.-M. Valentin com a colaboração de B. Banoun, J.-L. Besson, A. Combes, J. Lorang, F. Maier-Schaeffer e M. Silhouette, Paris, Editions Gallimard ("Bibliothèque de la Pléiade"), 2000, pp. 243-350.

10 A. Boal, Théâtre de l'opprimé, op. cit., p. 8.

11 Ibid., p. 48. 
ção"12. É dessa maneira que poderia ser sinteticamente definida a transformação de função proposta por Boal. Brecht promoveu a inserção do teatro nas lutas de classes - a partir do qual houve um incontestável salto qualitativo que modificou, consequentemente, as funções originais -, mas ele rejeita a sua assimilação ao processo revolucionário. Ele permanece na periferia, conduzindo-o ou preparando-o. Para Boal, o teatro é, nesse contexto, parte integrante, sendo um dos momentos, ou melhor, uma das experiências desse processo. Ele já é um "fazer" na trajetória revolucionária - sem poder, certamente, incorporá-la sozinho e sem substitui-la ("O teatro não é superior à ação. É uma fase preliminar. Ele não pode substitui-la. A greve vai ensinar mais"13).

\section{Emancipar o espectador}

A justificativa e a explicação da provocação proposta por Boal se sustenta em uma analogia com a décima-primeira "Tese sobre Feuerbach" de Marx: "Marx disse algo como: Chega! de uma filosofia que interprete o mundo. É preciso mudar a realidade. Marx poderia, talvez, sugerir alguma aproximação com o teatro"14. É à luz desse "fazer" que devem ser lidas as severas críticas que Boal endereça à posição do "espectador"(“[...] espectador é uma palavra obscena. O espectador é menos que um homem. É necessário humanizá-lo e Ihe devolver sua capacidade de agir plena-

12 A. Boal, Jeux pour acteurs et non-acteurs. Pratiques du Théâtre de l'opprimé, op. cit., p. 26

13 A. Boal, Théâtre de l'opprimé, Paris, Librairie François Maspero (“Petite Collection Maspero"), 1997, p. 186.

14 Idem, p. 185 mente"15), sendo esse o principal objetivo da "poética do oprimido": "transformar o povo, 'espectador', ser passivo do fenômeno teatral, em sujeito, em ator capaz de agir sobre a ação dramática"16, priorizando esse "princípio": "transformar o espectador em protagonista da ação teatral e, por meio dessa transformação, [...] buscar modificar a sociedade e não [...] se contentar somente em interpretá-la"17. A acusação endereçada contra o espectador sobrepõe intencionalmente duas posições, a do espectador de teatro e a do espectador da história. A proposição pode, então, ser estabelecida assim: para a história ser revolucionária é necessário que as massas se transformem de espectadoras em atrizes de seus próprios destinos - e é desta maneira que se encerra a narração da história revolucionária. Pesa, assim, sobre a posição "espectatorial" uma condenação, cujos riscos são evidenciados em algumas linhas de Frantz Fanon:

Sim, é necessário compreender que todo mundo integra o combate pela salvação comum. Não há mãos puras, não há inocentes, nem espectadores. Todos integramos o mecanismo, sujando nossas mãos no pântano de nosso solo e no espantoso vazio de nossos cérebros. Todo o espectador é um covarde ou um traidor. ${ }^{18}$

É possível integrar essa "metáfora" do espectador em um corpus de escritos revolucionários e de percebê-la como um dos alicerces das concepções da dinâmica revolucionária.

15 lbid., p.47.

16 Ibid., p.14.

17 . Boal, Jeux pour acteurs et non-acteurs. Pratiques du Théâtre de l'opprimé, op. Cit, p. 256.

18 F. Fanon, Les Damnés de la terre (1961), com prefácio de J.-P. Sartre e apresentação de G. Chaliand, Paris, Editions Gallimard (“Folio"), 1991, p. 242. 
Assim, ao "espectador" são vinculados alguns significados pejorativos preconcebidos (mas não sem problematizar): passividade ${ }^{19}$, inatividade, ociosidade, egoísmo, etc. Sabemos que a construção positiva de um "espectador da história" foi, aliás, objeto de veementes discussões nos últimos anos, na esteira notadamente de estudos e interpretações de $\mathrm{H}$. Arendt e J-.F. Lyotard, após um longo período de valorização quase exclusiva do "ator da política e da história"20.

O TO se constitui ao importar a crítica do espectador da história para o campo teatral. Trata-se de um tema recorrente nos trabalhos dramáticos e cinematográficos radicais dos anos 1960-1970 (pensemos, entre outros, em Guy Debord, Armand Gatti21, Fernando Solanas, etc.). Mas vincula-se, na obra de Boal, e isso a singulariza, a uma preocupação muito contundente em defender o valor da representação e, em consequência, das mediações. À representação "confiscadora", ele opõe não verdades "objetivas" mas, de fato, uma outra representação que encontra, contudo, sua legitimidade e sua utilidade na atuação realizada pelos próprios oprimidos, resultando em uma fragilização das interpretações a partir dos processos delegatórios. Dessa forma, Boal defende a produtividade do jogo e das situações ficcionais, na insubstituível intervenção

19 Em geral, diz Freud, vocês empregam a palavra viril com o significado de ativo e a palavra feminino em um significado passivo (...) Não é seguro que vocês tenham encontrado, fazendo isso, alguma coisa de essencial". Citado in G. Hocquenghem, La Dérive homosexuelle, Paris, Editions Universitaires Jean-Pierre Delarge, 1977, p. 45. A referência apresentada é Freud, "La féminité", nouvelle conférence, 1936.

20 Sobre essa questão, ver C. Ruby, L'Archipel des spectateurs du XVIIle au XXle siècle, Besançon, Nessy Editions, 2012, pp. $61-75$ et $123-140$.

21 Ver O. Neveux, "Un spectacle sans spectateurs, rien que des créateurs", in C. Brun, O. Neveux (número dirigido por), AG. Cahiers Armand Gatti, $n^{\circ} 1,2010$, pp. 110-135. dos corpos. Contesta, originalmente, o declínio da "divisão social do trabalho" no próprio dispositivo teatral - não somente dentro das modalidades de sua produção - e a justificada separação entre quem fala e quem escuta, quem joga e quem observa, quem cria e quem assiste. "É necessário libertar o espectador de sua condição de espectador"22, e, se possível, proporcionar ao oprimido o gosto do controle de seu destino.

\section{O espectador emancipado}

É essa concepção "ontológica" do espectador, como ser inerte e pacífico, ocioso e desenganado, que se reconhece, entre outras, na recente obra de Jacques Rancière "O Espectador Emancipado". Ele adota um ponto de vista polêmico a respeito do "teatro crítico" e suas metamorfoses, sem defender uma arte "pura" e "despolitizada", mas enfocando os programas que esse teatro se atribui e as emancipações que presume. De qualquer maneira, ele propõe inscrever o "teatro político" na história do "pensamento crítico" e de suas contradições, de suas absorções pela dominação, da necessária instabilidade de suas subversões e contestações. A partir dessa perspectiva, Rancière relembra o quanto todo um segmento do teatro político se constituiu com o intuito de ativar o espectador (e de organizar essa atividade). Haveria lugar, segundo ele, para desordenar as rotas assim estabelecidas porque "[a] emancipação começa quando colocamos em questão a oposição entre observar e agir, quando compreendemos as evidências que estruturam os vínculos do dizer, do ver e do

22 A. Boal, Théâtre de l'opprimé, op. cit., p. 185. 
fazer, como pertencentes, eles próprios, à estrutura de dominação e sujeição"23. Existe assim, nessa questão, um litígio que opõe duas concepções de emancipação. A antagônica percepção de "espectador" não é mais que um pequeno fragmento de um conjunto de coneepções divergentes. Dois extremos, dentre outros, permitem medir os labirintos dos bastidores do significado de "emancipação".

O primeiro refere-se à radicalidade do "método da igualdade" que Rancière constrói com base em Joseph Jacotot, contrapondo-se à "lógica do sistema explicativo": "Antes de ser o ato do pedagogo, a explicação é o mito da pedagogia, a parábola de um mundo dividido entre espíritos sábios e espíritos ignorantes, espíritos maduros e imaturos, capazes e incapazes, inteligentes e burros" ${ }^{24}$. De modo aparentemente similar, o método Boal pretende livrar a atividade teatral de didatismo dominante, à renovada desigualdade entre um palco (sabedor) e uma plateia (ignorante), oriundos de um vanguardismo trazido do "exterior" aos oprimidos. No entanto, malgrado as inumeráveis explicações do próprio Boal quanto à responsabilidade política do "Coringa"

23 J. Rancière, Le Spectateur émancipé, Paris, La Fabrique Editions, 2008, p. 19. E ainda: "[...] a oposição do ver ou fazer se reporta, imediatamente, quando opomos à cegueira dos trabalhadores manuais e dos praticantes empíricos, empurrados para o imediato e o terreno, à larga perspectiva desses que contemplam as ideias, prevendo o futuro ou propagando uma visão global de nosso mundo. [...] Os termos podem mudar de sentido, as posições podem ser trocadas, o essencial é que a estrutura permanece opondo duas categorias, os que possuem uma capacidade e os que não a tem", p. 18-19.

24 J. Rancière, Le Maître ignorant. Cinq leçons sur l'émancipation individuelle, Paris, Librairie Arthème Fayard ("10/18), 1987, pp. 15-16.

$25 \mathrm{Em}$ um primeiro momento, uma peça é apresentada aos espectadores. Ela representa as situações de opressão concretas. Depois da representação, algumas cenas serão reencenadas; aquelas que expõem um conflito de vontades entre os personagens (os oprimidos) que desejam modificar o curso dos acontecimentos e aqueles que os reduzem ao silêncio ou resistem à mudança (os opressores). Nessa segunda parte
"Um dos atores deve exercer tanto a função auxiliar de Coringa, de condutor do jogo. Ele deve explicar as regras do jogo, corrigir os erros cometidos e encorajar uns e outros a não interromperem a cena"26 - os dois "métodos" não podem ser tidos como equivalentes. Não se trata, portanto, de rotular, como foi feito em um texto, doravante famoso, no qual Bernard Dort caracterizou uma sessão de teatro-fórum como suposta e insidiosamente manipuladora ("[...] existe também a pressão, a espera de um público tão exigente que seus participantes podem, a qualquer momento, te 'abater' e pegar o teu lugar na cena. Quando o espectador-ator, longe de falar na primeira pessoa, não vai mais longe que a terceira, ao invés de ser ele mesmo, não se torna mais que um ator, e, seguidamente, um ator medíocre?" ${ }^{27}$, mas de buscar relatar os pressupostos políticos dessa teoria da prática à luz da crítica de Rancière - como "reveladora" das desigualdades irrefletidas do trabalho. A hipótese seria que, ao postular a neutralidade das técnicas ("Tu ofertas os meios de produção a um grupo e ele faz o que quiser. Tu deves aceitar a regra do jogo até o final. Tu corres esse risco. Tu não podes pensar em manter o teu poder, assegurando, assim, o teu controle. Eu ofereço minhas técnicas, elas [um grupo de mulheres com quem ele trabalhou em Nova York] suas imagens"28),

intitulada "fórum, um coringa expõe a regra do jogo, propondo aos espectadores que entrem em cena e atuem suas próprias alternativas ao substituírem os personagens oprimidos buscando transformar as situações propostas". M. Chatelain, Dans les coulisses du social. Théâtre de l'opprimé et travail social, Toulouse, éditions érès ("Trames"), 2010, p. 22.

26 . Boal, Jeux pour acteurs et non-acteurs. Pratiques du Théâtre de l'opprimé, op. cit., p. 60.

27 B. Dort, Le Spectateur en dialogue. Le jeu du théâtre, prefácio de J. Lassalle, Paris, P.O.L., 1995, p. 95. O texto é de 1983.

28 A. Boal, Théâtre de l'opprimé, op. cit., p. 198. 
e assim, por meio de dados historicizantes, Boal esvazia o poder contraditório e os instala em um dispositivo acabado. Portanto, há somente retificações internas ou inerentes ao método; é onde Boal não se priva: informado e consciente da fragilidade das ferramentas, ele continuou a alertar contra possíveis abusos do teatro, pondo em evidência, escrupulosamente, os impasses e as dificuldades: "O Coringa deve evitar todo o gesto que possa manipular ou influenciar o espectador. [...] O Coringa não decide nada por si mesmo. [...] O Coringa precisa reapresentar constantemente as questões para o público, para que seja ele quem decida"29. A esse respeito, também é possível ler seus numerosos escritos como a soma de alterações e de detalhes advindos da experiência, vinculados a uma prática que objetiva fortalecer o potencial emancipador (e dissociá-la dos usos alienantes ou normatizadores). Mas essas advertências dificultam uma questão mais radical, sendo o Coringa o mais igualitarista dos praticantes: como não reproduzir a dinâmica "embrutecedora"? Porque se não é o próprio Coringa que sabe o que fazer, sendo o téorico da emancipação dos outros, não é, inevitavelmente, ele que define o campo do que será debatido? Na linguagem de Rancière, isso é nomeado como "consenso": "O consenso não é a paz. [...] O consenso significa, com efeito, não o acordo das pessoas entre si, mas o acordo do sentido com o significado: o acordo entre um regime sensível de apresentação das coisas e um modo de interpretação desses sentidos"30. Não existe nesse modo de cartografar o espaço da discussão, de organi-

29 A. Boal, Jeux pour acteurs et non-acteurs. Pratiques du Théâtre de l'opprimé, op. cit., pp. 264-265.

30 J. Rancière, Chroniques des temps consensuels, Paris, Editions Galilée, 2005, p. 8. zar o pensável - e, com ele, suas consequências táticas e estratégicas - o "risco" latente de ordená-lo à lógica de um saber dóxico o que não é, na melhor da hipóteses, mais do que alguma informação discutível (como a necessidade de práticas unitárias, por exemplo)? E mais ainda, a sessão de teatro-fórum se organiza por meio do princípio da ignorância daquilo que nos preocupa, das estruturas que nos regem - malgrado nosso. Ela existe por meio do oculto, do "desconhecimento", revelando, portanto, uma orientação: "Lá onde pesquisamos o oculto sob a aparência, instauramos uma posição de dominação"31. Uma proposição de Boal interroga:

[...] o Coringa precisa ser socrático dialeticamente - e, através das questões, através das dúvidas, deve ajudar os espectadores a formularem seus pensamentos, a preparar suas ações. Maiêutica: o "Coringa" é um parteiro. Mas uma maiêutica de corpo e dealma, não simplesmente cerebral. O Coringa deve ajudar o parto de todas as ideias, todas as ações! ${ }^{32}$

Uma afirmação de Rancière pode fazer eco dessa orientação :

A figura socrática é evidentemente uma figura central porque Jacotot a responsabiliza como a figura que tradicionalmente representa o professor emancipador diante do professor autoritário: Sócrates, descendo a rua, fala a seu interlocutor e deduz a verdade que ensina na mesma progressão que a constitui na presença dele. Todo o trabalho reflexivo de Jacotot procura demonstrar que a figura de Sócrates não é somente aquela do

31 Ver J. Rancière, "Le coup double de l'art politisé, Lignes, $\mathrm{n}^{\circ}$ 19, fevereiro de 2006, republicada em J.Rancière, Et tant pis pour les gens fatigués. Entretiens, Paris, Amsterdam, 2009, p. 501.

32 A. Boal, Jeux pour acteurs et non-acteurs. Pratiques du Théâtre de l'opprimé, op. cit., p. 266. 
emancipador mas também aquela doembrutecedor por excelência, que organiza uma representação onde o aluno precisa, por si próprio, confrontar as lacunas e os paradoxos de seu próprio discurso: Jacotot aponta que esse é o método mais embrutecedor, se entendermos como embrutecedor o método que faz penetrar no pensamento daquele que fala o sentimento de sua própria incapacidade. $\mathrm{O}$ embrutecimento é, essencialmente, o que constitui o método que faz alguém falar para que possa concluir que o que disse é inconsistente e que ele nunca teria reconhecido que o que tem em mente é inconsistente, se alguém não tivesse lhe mostrado o caminho para demonstrar a si mesmo a sua própria insuficiência. ${ }^{33}$

Podemos, certamente, contestar a caracterização de Sócrates que propõe Rancière ou sublinhar o diálogo impossível: de um (Boal) com outro (Rancière), pois não se trata de designar um processo similar - e o TO não ignora a dificuldade: "Atenção, em cada Sócrates, há um evangelista adormecido", alerta Jean-Gabriel Carasso ${ }^{34}$. No entanto, falta reconhecer a ambivalência (em estado indissolúvel) que sustenta o TO. Demarquemos: Rancière não é o parâmetro ao qual se reportam todas as ideias de igualdade, assim como não é o avaliador de níveis de emancipação de um dispositivo. No entanto, ele veio inquietar as práticas e os discursos. Ele se interessa em questionar a "maiêutica" no trabalho de uma sessão de teatro-fórum, não somente à luz de uma crítica às pressões exercidas pelo coletivo -essa crítica é sistematicamente endereçada a todas as as-

33 J. Rancière, "L'actualité du Maître ignorant, entrevista realizada por A. Benvenuto, L. Cornu e P. Vermeren, Télémaque, 2005, reprisada in J. Rancière, Et tant pis pour les gens fatigués. Entretiens, op. cit., p. 411.

34 J.-G. Carasso, "Petit dictionnaire du Théâtre de l'opprimé", Théâtre de l'opprimé. Bulletin d'information du Centre d'étude et de diffusion des techniques actives d'expression (méthode Boal), número 6, 1982, p. 49. sembleias políticas (como as assembleias gerais) - , nem àquelas possivelmente derivadas desse mecanismo, mas enfocando o relato explicativo - a necessidade da "explicação" - que essa proposta avaliza. Mesmo que o coringa não "saiba" mais que aqueles que jogam, ele encarna o "recurso" explicativo, não necessariamente exercendo-o, mas tendo poder para fazê-lo. Algo deve ser sempre explicado - e o Coringa assegura a presença desse princípio, seja ela, até aquele momento, inativa.

Dessa forma, parece que a singularidade política produtiva do TO não se encontra, como tanto se discursa e insiste, no surgimento de uma fala autêntica dos sujeitos oprimidos ou na possibilidade efetiva de suas expressões liberadas (Boal também desconfia de um certo "espontaneísmo": "É, de fato, muito difícil de fazer um espectador - acostumado a ser passivo sempre - um ator. Nós não podemos agir como se fosse possível dizer às pessoas que vêm ao teatro-fórum, na entrada do jogo: Vamos lá ! digam e mostrem como vocês pensam"35). Com o intuito de renovar, com a prática presumivelmente horizontal que propõe (e que bem seguidamente é postulada como inata), o TO necessita, talvez, de ser exercido onde não existem homogeneidades "políticas" prévias sem julgar seu valor nesse contexto nem mesmo reconhecer que elas atribuem uma certa superioridade a esses "coletivos". Não é para diminuir sua importância: as organizações, os movimentos, as redes, as associações espontâneas supõem também os espaços de deliberação, de projeção, de mediação, de exposição das contradições (internas ou externas)... Trata-se aqui de propor a substituição de uma

35 A. Boal, "Le "Théâtre de l'opprimé. (Entrevista com Augusto Boal, Emile Copfermann, Patrick Sempéray e Pierre Razdac)", entrevista citada, p. 35. 
lógica de formação - a emancipação supõe a "deformação" dos contornos - "dos ignorantes pelos sábios, dos homens metidos nas preocupações materiais egoístas pelos homens devotados, fechados no seu particularismo pelo universal da razão e do poder público"36, uma lógica de elaboração coletiva: uma auto-formação composta pelas perspectivas e conhecimentos comuns que a fizeram necessária. Ao invés de "aumentar o círculo dos conhecedores", assim como Brecht pretendia com o teatro popular, o TO sustentaria o objetivo de afinar, aguçar e problematizar os círculos já militantes (sem deixar de evocar a intenção do Lehrstück brechtiano em suas peças "escritas $^{37}$ para serem jogadas entre si"38), assumindo-se comomediadoras nas (e até mesmo das) mediações. De trabalhar para si mesmo e não para os outros - no "interior" e não do "exterior" - sob pena de participar dessa distribuição hierárquica de capacidades e de registros que postulam, em um mesmo movimento, aparentemente contraditório, a autoridade dos "sábios" - aptos a configurar o espaço do pensável e as ferramentas impostas por ele - e a soberania que não considera a experiência dos "provocadores"39. Boal já escreveu :

36 J. Rancière,Le maître ignorant, op. cit. p. 218.

37 No original [é]crites, jogo com a palavra, de difícil tradução. (N.T.)

38 B. Brecht citado por P. Abraham, in Europe: Brecht, janvier-février 1957, nos 133-134, p. 173. Sobre o Lehrstück, ver P. Ivernel, "Grande pédagogie: en relisant Brecht", in J.-P. Sarrazac (textos reunidos e apresentados por), Les Pouvoirs du théâtre: essais pour Bernard Dort, Éditions théâtrales, Paris, 1994, pp. 215-227.

39 É possível relembrar aqui um comentário de Rancière "Rapidamente, pudemos constatar os limites da crítica do porta-voz da necessidade de autenticidade, que só fala, de fato, aquilo que está autorizado a dizer. Percebe-se, naqueles anos, um aspecto ambíguo: de um lado, o questionamento daqueles que falam em nome da ciência, que defendem um universo discursivo partido em dois, mas também, do outro lado, alguma coisa que se tornou muito forte, em sua época,
O teatro-fórum deve ser feito pelos espectadores organizados, sua audiência precisa estar organizada. Não é possível fazer o teatro-fórum por e com pessoas que não se conhecem, mas por um grupo, uma coletividade de trabalho, de estudantes universitários, de membros de uma associação, um movimento feminista ou habitantes de uma favela. ${ }^{40}$

À luz da poderosa derrota política e social dos movimentos de emancipação no Ocidente nas últimas décadas, e da fraqueza da política radical organizada, essa necessidade pode ter sido mais aguda para não sucumbir à dinâmica valorizante - aparentemente generosa - mas "embrutecedora" como processos socráticos e à atração que a "lógica da ignorância" pode exercer. Em suma, para não deixar a sociedade - e cada um - num estado de partilha que, ainda hoje, a sutura.

A essa altura, intervém um segundo ponto de embaraço. Trata-se da consistência desse saber e refere-se à caracterização desse teatro como sendo do "oprimido" (proprietário e/ ou destinatário?) em uma filiação reivindicada, mas parcial, com os escritos de P. Freire e de sua "Pedagogia do Oprimido", a qual, como resume Julian Boal, propõe relações que não "sejam mais verticais e hierárquicas, mas dialéticas": "A educação visa, segundo a pedagogia do oprimido, não o ato de depositar o conhecimento, mas de aguçar o senso crítico"41. Rancière explica o que o distingue da aproximação de Freire (malgrado as evidentes proximidades como a reprovação de uma "vi-

servindo à tirania da autenticidade. De qualquer maneira, o PC sempre jogou com os dois registros: de um lado, a ciência; do outro, as pessoas que são "verdadeiramente" operárias. J. Rancière, La Méthode de l'égalité, op. cit., p. 47.

40 A. Boal, Théâtre de l'opprimé, op. cit., p. 189.

41 J. Boal, in M. Chatelain, op.cit., p. 24. 
são bancária da educação"; "o conhecimento é uma doação daqueles que julgam que são sábios àqueles que eles julgam ignorantes"42):

A pedagogia do oprimido se ocupa de relacionar a educação geral com a educação política. Eu penso então que se existe alguma coisa em comum entre as duas, é a ideia de que a instrução significa, em primeiro lugar, a descoberta de uma capacidade, da capacidade que possuem tanto os oprimidos quanto as "classes desfavorecidas". Por outro lado, é verdade que a emancipação intelectual significa que não há uma pedagogia específica do oprimido, nem uma educação especificamente adaptada aos pobres e oprimidos. Ou, se existe uma pedagogia própria aos oprimidos, deve-se pensá-la como um caso particular de uma ideia geral da emancipação intelectual. Porque, fundamentalmente, a ideia de emancipação é a mesma para os ricos e para os pobres. ${ }^{43}$

A formulação colide frontalmente com as concepções dominantes na esquerda, da emancipação como um processo segmentado, ou ao menos, diferenciado do olhar que se emancipa. Essa contestação da "cultura popular", das "culturas menores", das "culturas dos oprimidos" tem por principal virtude a de interpelar os pressupostos dos processos emancipadores.

Boal sempre foi cauteloso em relação a uma apreensão não-dinâmica e não-relacional da categoria de oprimido. Ele chegou a propor

42 P. Freire, Pédagogie des opprimés, seguida da Conscientisation et révolution, traduzida do português brasileiro, Librairie François Maspero, 1980, p. 51.

$43 \mathrm{~J}$. Rancière, "L'émancipation est-elle une chose du passé?", entrevista realizada por L. Liang e L. Gardens, 2009, retomada in J. Rancière, Et tant pis pour les gens fatigués, op. cit., p. 656. Lê-se, também, sobre Rancière e Freire : W. Kohan, Rancière et l'éducation. Forces et limites - philosophiques et politiques - d'un antiprogressisme", in L. Cornu, P. Vermeren (textos reunidos por), La philosophie déplacée. Autour de Jacques Rancière, Editions Horlieu, 2006, p. 429-440. uma caracterização surpreendente suscetível de impedir ou minar as estruturas clássicas: "Os opressores oprimem os oprimidos de todas as maneiras possíveis, e a pior de todas é aquela que impede sua capacidade de metaforização da realidade" ${ }^{44}$. Mas essas definições (e previsões), no entanto, não levam à deduzir, como Rancière, que a emancipação necessita, de qualquer forma, ignorar a dominação, "de não admiti-la" ${ }^{45}$, como conclui Rancière de sua leitura de arquivos operários do século XIX:

[...] Eu procurei um pensamento que fosse oriundo dos operários, que emanasse realmente da classe, das práticas de oficina, das culturas populares. [...] Eu me achei diante de uma série de manifestações explosivas, divergentes, seguidamente paradoxais, em um sentido no qual elas não correspondem, verdadeiramente, às expectativas. [...] Eu tentei construir uma rede de relatos e de razões a partir das quais um certo número de indivíduos operários do século XIX buscou sair de sua condição, buscou pensar uma saída. Não simplesmente o fato de encontrar a teoria que os libertaria, mas para o fato de construir modos de vida, de percepção e de pensamento que já são uma ruptura da relação com uma identidade operária imposta. ${ }^{46}$

Constatada a importância da sugestão de renunciar a toda "massificação teórica" dos processos de emancipação - é necessário, portanto, contrapor todo o malentendido, sem reclamar ou abandonar a questão emancipatória, nem sua diluição, mas com a preocupação de examinar os fenômenos concretos. A

44 A. Boal, "Le Théâtre de l'opprimé", entrevista concedia a O. Neveux, Rouge, $n^{\circ} 2075,29$ de julho de $2004 A$

45 J. Rancière, Le Philosophe et ses pauvres, Paris, Editions Flammarion (Champs"), 2007, p. XI.

46 Rancière, "Déconstruire la logique inégalitaire, entrevista realizada por P.-V. Cresceri et S. Gatti, 2008, Et tant pis pour les gens fatigués, op. cit., p. 642-643. Eu destaco. 
emancipação rompe com a ordem que regra, historicamente, os lugares e as condições. Ela é uma operação de desidentificação. Apontamos, então, a dificuldade: como planejar essa desidentificação? Como, precisamente, não impedi-la com o jogo de nominações, designações e explicações que são supostos como "espontâneos" em certas "teorias de emancipação"? Como não fixar em invariantes estabilizadoras o que deve ser um oprimido e remeter cada um a um lugar estabelecido por uma cultura, uma condição, um horizonte de suposta origem ou finalidade? Como não obstruir demasiadamente os "marcadores" de identidade, desestabilizando categorias que, precisamente, estruturam-se na estabilidade, sem omissões nem excessos do campo social?

Pode-se sustentar, certamente, que o TO não inclui em seu projeto a emancipação "intelectual" (conforme definida por Jacotot) - como destaca Audrey Olivetti: "o objetivo do TO é, prioritariamente, desindividualizar as situações, rompendo com o psicologismo e contrariando as lógicas sistemáticas de opressão"47. Além disso, é possível objetar que o poder da dominação assim como a dimensão coletiva estão entre os pontos opacos ou refutados do "Espectador emancipado" - no sentido que interessa à Rancière de não mostrar como "escapar das garras de um tipo de monstro tentacular, mas de conceber a possibilidade de condução por meio de outro viés distinto do que está em curso"48. Mas essa observação, em contrapartida, deixa em suspenso, preci-

47 A. Olivetti, in M. Candore, "Muktadhara : un film-documentaire sur les Rencontres internationales du Théâtre de l'Opprimé et les pratiques du Jana Sanskriti Calcutta, 2010. Entrevista com A. Olivetti, in A. Querrien, F. Garcin-Marrou, M. Candore (número coordenado por), Chimères: Squizodrame et schizo-scènes", n80, Toulouse, Erès, 2013, p. 159.

48 J. Rancière, La Méthode de l'égalité, entrevista com L. Jeanpierre et D. Zabunyan, Paris, Editions Bayard, 2012, p. 112. samente, a questão da "emancipação intelectual" dentro do TO.

\section{- Os modelos de ação para o futuro ${ }^{49}$}

Enfim, parece que o conjunto dessas observações é oriundo de uma concepção divergente do "tempo" da política e, por consequência, de sua definição. É notável, com efeito, que Boal não cessa de orientar seu trabalho e a utilidade do TO por meio do porvir - sendo esse o ponto que o distingue do psicodrama: "Acredito que o psicodrama se preocupa sobretudo com o passado, o teatro-fórum, com o futuro, com os problemas vindouros"50. A proposição se vincula às perspectivas combatentes clássicas: a perspectiva de um combate futuro, o qual é necessário antecipar e preparar. Essa poderia ser, à propósito, uma das profundas diferenças que distinguem esse teatro de outras propostas políticas do teatro contemporâneo. É possível considerar as formas e os dispositivos, seguindo a proposição de Ernst Bloch, como uma experiência no presente de "pré-demonstração de um mundo concretizado"51, Boal opta, de qualquer maneira, pela experiência no presente da pré-demonstração da luta que conduzirá, possivelmente, ao mundo concretizado. O TO é conhecido como o "ensaio da revolução". Tal abordagem não pretende substituir a revolução pelo teatro, ao imitar seus temas, mas assume ser um "ensaio", "tentativa", "experiência", parcial e fictícia, útil a seu futuro acontecimento: "se nos

49 A. Boal, Jeux pour acteurs et non-acteurs. Pratiques du Théâtre de l'opprimé, op. cit., p. 26.

50 A. Boal, Théâtre de l'opprimé, op. cit., p. 189.

51 Ver O. Neveux, Politiques du spectateur. Les enjeux du théâtre politique aujourd'hui, Paris, La Découverte, 2013. 
dermos os meios de ponderar o impoderável, a imponderabilidade será menor" ${ }^{52}$. Certamente, o programa é ambicioso, mas supõe, previamente, que as formas e normatizações da revolução (ou de uma ação coletiva como, por exemplo, uma greve) possam, em parte, pensar e antecipar (sendo possível medir à distância, em perspectiva, em prazo maior ou menor, como nos anos 1960, a amplitude da luta que modificou funções e tarefas) ou, ainda mais importante: que elas "devam"antecipar. A dificuldade é dupla. Em um primeiro momento, ela tem a mesma consistência da categoria de "revolução" (ou de acontecimento político): vã e absurda pretenção, como Jean Genet optou por pensar.

Seria o equivalente de reconhecer uma lógica na incoerência das imagens sonhadas. Se o tempo está seco, é inútil prever as etapas necessárias para atravessar o rio em caso de cheia quando a ponte estiver inundada. Em um estado de certa sonolência, a revolução me parece como a cauda de um tigre enjaulado que inicia um floreio hiperbólico e, cansada, reduz sua curva ao lado da fera ainda presa. (Tradução livre.) $)^{53}$

Isso também pode ser dito, nos termos de Rancière, por meio de uma questão: o futuro é conhecido ou está por ser inventado?"54 A

52 A. Boal, "Le Théâtre de l'opprimé. (Entrevista entre Augusto Boal, Emile Copfermann, Patrick Sempéray e Pierre Razdac)", entrevista citada, p. 26.

53 "[ce] serait l'équivalent, au réveil de vouloir la logique dans l'incohérence des images rêvées. Il est vain d'inventer, si le temps est au sec, les gestes nécessaires pour mieux traverser la rivière quand la crue emportera le pont. Dans une demi-somnolence, en songeant à elle, la révolution m'apparaît ainsi la queue d'un tigre encagé commence un paraphe hyperbolique qui rabat sa courbe lassée sur le flanc du fauve toujours en cage."InJ. Genet, Un Captif amoureux, Paris, Editions Gallimard (“Folio"), 1986, pp. 504-505.

54 J. Rancière, Politiques de la "mésentente", entrevista com D. Bensaïd e O. Neveux, Contretemps, 2008, reprisada in J. Rancière, Moments politiques. Interventions 1977-2009, Lux dificuldade é ampliada quando há o questionamento sobre se é desejável prever, pensar ou ensaiar a revolução. Como é possível vislumbrar ensaiá-la (independente do que isso signifique nesse caso) se não por meio da modelização de suas características e processos, do cerceamento de novas possibilidades ou de reviravoltas sem precedentes e imprevisíveis - sem ilusões, entretanto, sobre a novidade completa que configura a situação? Uma vez mais, Rancière apresenta uma estrondosa objeção: "A arte da emancipação consiste justamente na recusa da relação entre os meios e os fins, a qual, na tradição de esquerda, é representada pela ideia de criar as armas do futuro, as condições de um melhor porvir, o que pressupõe uma certa fé nessa necessidade histórica"55. Posição difícil que permite, por sua radicalidade, interrogar o que a visão estratégica pode obscurecer, restringir e parar de pensar. É o que se afirma aqui, em um ponto de tensão - porque não é evidente que se deve desistir de todo o horizonte estratégico - devido à recusa de identificar o futuro almejado e as formas que conduzem a ele, além da decisão de se abrir à contingência e à criação do presente. Surgem duas concepções da política. Para dizer de forma exageradamente esquemática, uma defenderá que ela é um

Éditeur - La Fabrique, Montréal (Canadá) - Paris, 2009, p. 185. A citação completa é: "Meus questionamentos dizem respeito à pretensão de saber até onde vai a dinâmica igualitária e o risco permanente de uma prioridade acordada do interior da coletividade com atenção ao próprio presente dos atos políticos e àqueles que poderão resultar desses no futuro", p. 184-185.

$55 \mathrm{~J}$. Rancière, L'émancipation est-elle une chose du passé?", entrevista citada, p. 659: "O que é importante em A Noite dos Proletários é essa ideia de subversão do tempo que está situado aqui e agora. Meu foco é que a ideia do futuro, do tempo diferenciado, pertence a um uso interdito do tempo: "é possível enxergar algo no futuro, mas não no presente". O tempo é o álibi da interdição. Ver também J. Rancière, La Méthode de l'égalité, op. cit., pp. 107-108. 
processo de construção definido pela visão de seu objetivo (e que pressupõe, então, ensaios, repetições), correndo o risco de haver "militantes" surdos e cegos inventando as situações, incorporando uma linearidade ensaiada e recitada daquilo que uma luta deve ser composta e dos movimentos e etapas que ela compreende. Outra sustentará que "ela é sempre feita para defender a prolongação daquela abertura do possível, de um mundo de relações igualitárias que vêm romper uma ordem, um sistema de posições e funções, de identidades definidas" ${ }^{\text {, }}$, sob o risco de nadar conforme a maré, sob a atração de um presente sem passado nem futuro, à imagem "dum arco tensionado com uma flecha que não visa alvo algum"57.

De tudo isso, o que concluir provisoriamente ? Que as duas lógicas iniciais, com base em construções "teleológicas" ou históricas, que se identificam de acordo com argumentações teóricas do TO não possuem, seguindo os princípios estipulados por uma ou outra, consequências semelhantes e parece que a dinâmica histórica - a de uma ferramenta conjuntural - foi progressivamente deposta em favor da segurança 'teleológica' de ser uma etapa ou um estado - intransponível enquanto houver opressão. E, de fato, se o TO é a realização ou o ponto culminante do teatro político (sendo esse o motivo para a reconciliação com suas origens), então, ele pode, logicamente, se desinteressar do "outro teatro", e preocupado em afinar métodos e sistema, somente produzir alterações e correções intrínsecas.

56 J. Rancière, in A. Janvier, A. Cukier, La question politique de l'émancipation. Entrevista com J. Rancière", A. Cukier, F. Delmotte, C. Lavergne (sob a direção de), Emancipation, les métamorphoses de la critique sociale, Bellecombe-en-Bauges, Editions du Croquant, 2013, p. 143.

57 D. Bensaïd, Eloge de la politique profane, Paris, Albin Michel (“Idées"), 2008, p. 172.
A outra abordagem não oferece nem a estabilidade nem a imunidade que embasam a convicção de sua existência. Ela obriga ao desconforto da divisão incessante do que a emancipação pode designar, a igualdade pode encobrir e a política pode significar. Reconectar com a dimensão polêmica e negativa que iniciou o TO permitiria, nesse sentido, questionar alguns princípios, que se tornaram, atualmente, lugares-comuns tanto no teatro político, quanto nas lutas ocidentais e nas práticas do TO. Assim, revelar-se-ia útil, inspirando-se, enfrentando-se e se desacomodando, de se lembrar que há quase dois séculos "o início da liberdade para o pedreiro, em seu trabalho, consistia nessa inversão: ser aquele que observava e não mais aquele que era observado"58 e lembrar o quanto" a voz que evoca um sujeito trabalhador (oprimido/a) supunha todo um trabalho de desidentificação, de extirpação de uma identidade trabalhadora (oprimida) dada, inserida na transgressão por meio do pensamento e da fala dos outros" ou ainda de considerar que "[...] transformar o mundo, não é somente, mas é ainda interpretá-lo, como um texto cujos quarenta e nove graus de significação não se revelam jamais em um só golpe"59.

Recebido: 24/08/2017

Aprovado: 01/02/2018

58 J. Rancière, Introduction, in L.G. Gauny, Le philosophe plébéien, textos reunidos por J. Rancière, Paris, Editions La Découverte (“Actes et mémoires du peuple"), 1983, p. 15.

59 Bensaïd, D. La Discordance des temps. Essais sur les crises, les classes, l'histoire, Paris, Les Editions de la Passion, 1995, p. 218. 